\title{
Universities can learn too: Extracting the value stream from small-dollar transactions
}

\author{
Richard Palmer Ph.D., C.P.A., C.M.A. \\ Southeast Missouri State University \\ Mahendra Gupta, Ph.D. \\ Washington University in St. Louis \\ James Brandt, M.B.A. \\ RPMG Research Corporation
}

\begin{abstract}
Based on survey responses of 350 colleges and universities in North America in 2017, we find that the majority of benefits from purchasing card use are falling to a minority of card-using educational institutions. This study examines the extent to which $p$-card programs at colleges and universities in North America "fail to launch," and presents an outline for program selfassessment, identifies common obstacles in implementing a successful p-card program, and provides a roadmap to rehabilitate a languishing $p$-card program.
\end{abstract}

Keywords: Purchasing Card, Card Program Administration, Technology Implementation, Card Value, University, Survey Data

A handful of organizations and technology providers have recently identified ways in which the Accounts Payable cost center can be transformed into a profit center by measured changes to processes that improve operational efficiency, enhance liquidity, and promote a controlled expansion of purchasing card use (Bottomline Technologies \& BNY Mellon, 2017). These changes have enabled some colleges and universities to drive millions of dollars per year in spending to purchasing card (hereafter, $p$-card) platforms, yielding significant cash incentives from card issuers and notable internal process improvements and cost savings. The benefits from purchasing card use, including those among colleges and universities, have been documented over time in various studies (Herbst-Murphy, 2012; Paystream Advisors, 2012; Thorpe, 2016). These benefits include (a) a significant reduction in the administrative cost of procuring and paying for a good or service, (b) a significant reduction in the average procurement cycle time, (c) rebates and incentives associated with p-card spending, and (d) a simplified procurement process.

Notwithstanding the potential benefits of an "AP profit center," and while our survey research indicates that adoption of p-card technology by institutions of higher education is commonplace, significant challenges to the successful implementation of $p$-card programs remain. Specifically, this paper will show that a large percentage of total $p$-card spending among higher education card adopters is conducted by a relatively small segment of colleges and universities. We document that many higher education institutions have failed to launch their p-card program. In other words, the successful implementation of

PALMER, GUPTA, \& BRANDT / DOI: 10.5929/2019.1.14.4 
p-card technology has been an elusive achievement for many higher education organizations. In this respect, barriers to the successful implementation of a p-card program are not unlike barriers to implementations of other major technological change (Aiman-Smith \& Green, 2002; Baer \& Frese, 2003; Repenning \& Sterman, 2002).

Thus, the purpose of this paper is to provide insight, based on survey research data, to (a) assess the extent to which p-card programs at colleges and universities in North America "fail to launch," (b) present an outline for a program self-assessment, (c) identify common obstacles in implementing a p-card program, and (d) present a framework to rehabilitate an underperforming $\mathrm{p}$-card program.

\section{Data Source}

The data utilized in this study come from the "2017 P-Card Benchmark Survey" conducted by RPMG Research Corporation in the first quarter of 2017. The survey was released to over 16,000 p-card program administrators at organizations that were either customers of one of twenty major U.S. and Canadian card issuing banks, or members of the National Association of Purchasing Card Professionals or the National Institute of Governmental Purchasing. Three thousand five hundred eight responses were received for a $22 \%$ response rate, representing all major p-card brands (American Express, MasterCard, and Visa). Of the 3,508 respondents, $10 \%$ or 350 were colleges or universities (hereafter, "universities"), $13 \%$ were public corporations, $32 \%$ were privately-owned corporations, $5 \%$ were federal or state government agencies, $18 \%$ were city or county government agencies, $13 \%$ were school districts, and $9 \%$ were not-forprofit organizations. This paper will focus on universities' use of $\mathrm{p}$-cards.

\section{"Failure to Launch" with P-Cards}

The growth of $\mathrm{p}$-cards in the United States and Canada over the past twenty-five years has been consistent and strong, rising from near zero in 1993 to about $\$ 342$ billion in 2017. Universities comprised approximately $11 \%$ of the p-card spending in North America in 2017 (or about $\$ 38$ billion). Figure 1 shows that spending among universities was skewed toward a minority of institutions. Specifically, almost $74 \%$ of the spending reported among universities in the 2017 survey was concentrated in just $20 \%$ of respondents. In fact, the top $40 \%$ of universities generated $90 \%$ of total $p$-card spending while the bottom $60 \%$ accounted for the remaining $10 \%$ of spending. The same pattern existed within universities categorized by size, to wit: the vast majority of $p$-card spending among similar-size universities is conducted by $20 \%$ of the group. Thus, a relatively small segment of the university market was extracting most of the expected benefits from $p$-card use, while others were failing to capture the full value potential of the card program.

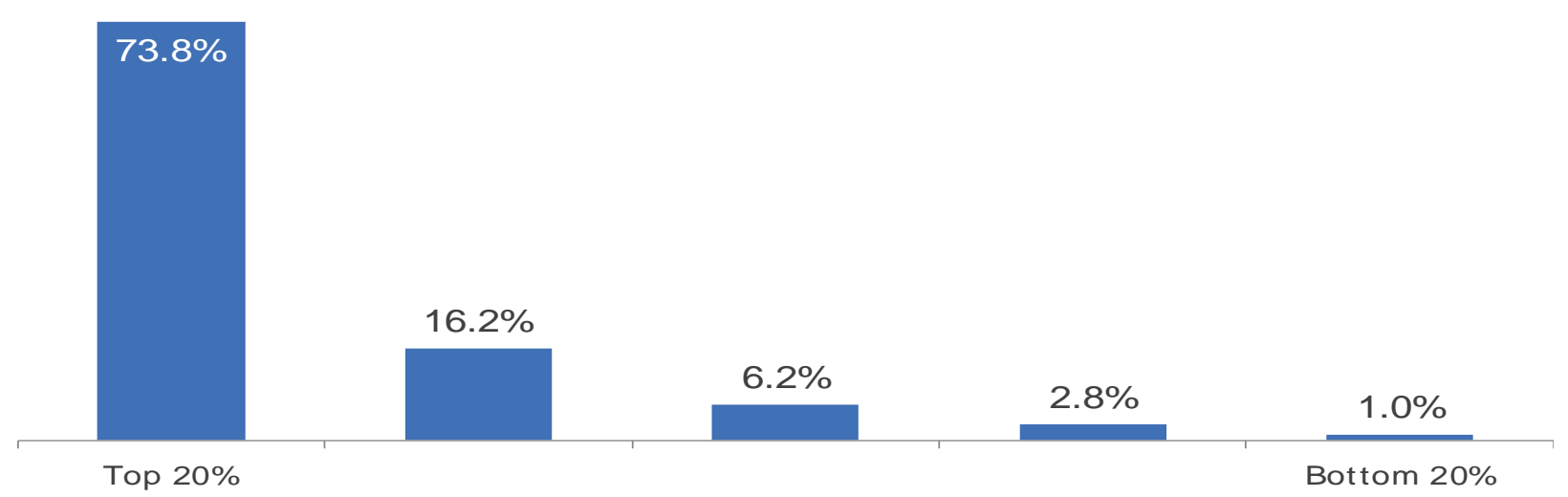

Figure 1. Distribution of P-Card Spending by Percentage of University Respondents.

PALMER, GUPTA, \& BRANDT / DOI: 10.5929/2019.1.14.4 


\section{Conducting a Program Self-Assessment}

An evidence-based evaluation of p-card program progress to date is a critical first step in any university plan to elevate the performance of its p-card program. However, a common problem among underperformers is a misdiagnosis of program progress. Our analysis of survey data in 2017 showed that $86 \%$ of programs that (based on benchmark performance metrics) "need improvement" had an inflated perception of their program performance that was inconsistent with the program performance of their peers. Thus, as a first step, a university should use objective benchmark data regarding $p$-card use of similarly-sized universities to compare and evaluate its own p-card program. Table 1 provides selected program statistics for small, mid-size, and large universities in the survey response. Aside from the notable difference in monthly spending, many program characteristics differed by university size, including the percentage of transactions (of varying size) paid with p-cards (higher among larger universities), average monthly card spending per employee (higher among mid-size universities), and pcard spending as a percentage of organization budget (higher among small universities).

Once a university makes a benchmark comparison of its performance to peer institutions, it can begin the process of evaluating its program choices and outcomes. For example, comparisons to benchmark data enable the university to not only understand how its spending compares to others but also provide insights into why spending is at its current level (e.g., is the university's card distribution or average transaction amount significantly different from its peers?).

Table 1

Key P-Card Program Statistics by Size of University

\begin{tabular}{lrrr}
\hline Card Program Statistic & Small & Mid-Size & Large \\
\hline Number of employees & 235 & 1,827 & 12,029 \\
Number of plastic p-cards & 50 & 427 & 2,052 \\
Card-to-employee ratio & $21.4 \%$ & $23.4 \%$ & $17.1 \%$ \\
Average monthly p-card spending & $\$ 57,304$ & $\$ 827,110$ & $\$ 4,741,402$ \\
Median monthly p-card spending & $\$ 50,000$ & $\$ 400,000$ & $\$ 3,539,267$ \\
Transactions \$2,500 or less paid by p-card & $43 \%$ & $52 \%$ & $67 \%$ \\
Transactions \$2,501 to \$10,000 paid by p-card & $14 \%$ & $23 \%$ & $37 \%$ \\
Transactions \$10,001 to \$100,000 paid by p-card & $1 \%$ & $9 \%$ & $14 \%$ \\
Monthly spending per employee & $\$ 244$ & $\$ 453$ & $\$ 394$ \\
Annual p-card spending as a percentage of budget & $3.83 \%$ & $3.68 \%$ & $3.51 \%$ \\
Monthly spending per card & $\$ 1,142$ & $\$ 1,937$ & $\$ 2,310$ \\
Monthly transactions per card & 6.00 & 6.35 & 6.22 \\
Spending per transaction & $\$ 190$ & $\$ 305$ & $\$ 371$ \\
Percentage of active cards in a typical month & $74 \%$ & $76 \%$ & $77 \%$ \\
\hline
\end{tabular}

Note: The different size categories are defined as follows: "Small" universities have an annual budget of less than \$25 million; "Mid-Size" universities have an annual budget of \$25 million or more and fewer than 5,000 employees; "Large" universities have 5,000 or more employees.

One can extend the analysis of university benchmark norms to other actions taken to implement and manage the card program. On the basis of survey responses, we find these actions can be broken into three categories: acceptance, control, and technology. These categories define the success factor of a $p$ card program and highlight common obstacles faced by card programs and their administrators. 


\section{Acceptance}

Consistent with research concerning the implementation of new technologies (Klein \& Knight, 2005), we find that successful p-card program implementations most often occur in organizations that embrace change. The embrace, or acceptance, of the new technology must occur at all levels of the workforce (administration, faculty, and staff) and extend across the supply chain (e.g., vendors). Thus, leadership support and the "tone at the top" regarding the role envisioned for the p-card program are very important. We note that the leadership is evident where organizational policies are adapted to promote card use, employee training is robust and comprehensive, communications about the card program accentuate the value derived from card use, and sufficient personnel resources are committed to program administration.

Employee acceptance, too, must be considered in the development of a successful p-card program. Our observation has been that employees often know the benefit of card use to the organization but fail to use cards if other "maintain the status quo" payment options remain available.

Additionally, acceptance of card payment by suppliers is vital to the success of the program. Some universities are currently "hitting a wall" in which p-card spending is limited by the number of suppliers willing to accept the payment method, which, in turn, limits overall program performance. In the 2017 survey, universities indicated that their p-card spending would grow an average of $45 \%$ if all suppliers began accepting $\mathrm{p}$-card payment. Universities that incorporated a supplier enablement strategy were more likely to overcome the acceptance obstacle.

Table 2

Selected Management Statistics of P-Card Program Acceptance by Size of University

\begin{tabular}{|c|c|c|c|}
\hline $\begin{array}{l}\text { Top Management Views } \\
\text { Percentage that agree or strongly agree that top } \\
\text { management... }\end{array}$ & Small & Mid-Size & Large \\
\hline $\begin{array}{l}\text { Fully support the } p \text {-card program } \\
\text { Expect } p \text {-card spending to be limited to specific } \\
\text { purposes }\end{array}$ & $83 \%$ & $79 \%$ & $73 \%$ \\
\hline Level of P-Card Program Resource Commitment & & & \\
\hline $\begin{array}{l}\text { Percentage that have at least } 1 \text { full-time } \\
\text { equivalent } p \text {-card administrator } \\
\text { Average number of cards managed by } 1 \text { full-time } \\
\text { equivalent administrator }\end{array}$ & $40 \%$ & $63 \%$ & 1,217 \\
\hline Card Program Management Benchmark & & & \\
\hline $\begin{array}{l}\text { Percentage that mandate the use of } p \text {-cards for } \\
\text { transactions below a certain threshold } \\
\text { Percentage that have a set strategy to enable } \\
\text { suppliers to accept } p \text {-card payment }\end{array}$ & $17 \%$ & $27 \%$ & $23 \%$ \\
\hline
\end{tabular}

As shown in Table 2, administrative leadership at small universities was more likely to fully support the $p$ card program than their larger counterparts but were also more likely to expect that card program to be limited to particular situations or purposes. Conversely, larger universities were more likely to have a set strategy to enable suppliers to accept $p$-card payment. Mid-size universities were more likely to mandate the use of $p$-cards for transactions below a certain threshold.

PALMER, GUPTA, \& BRANDT / DOI: 10.5929/2019.1.14.4 


\section{Control}

A key to successful implementation of a p-card program was the establishment of appropriate controls and policies associated with card use. One of the greatest impediments to a successful p-card program was simply "fear" of misuse by those in charge of university administration. In the survey, misuse was broken into three categories--fraud, employee misrepresentation, and policy violations. Fraud was defined to include card use by a third party (such as an internet hacker or an unscrupulous merchant) or personal use by a university employee who is not authorized to use the p-card. Misrepresentation was defined as any event in which an employee authorized to use the p-card, made a personal transaction with the $p$-card and misrepresented that transaction as a bona fide business charge. Policy violation was defined as a bona fide university $p$-card purchase, but the purchase was (a) with an unauthorized or "nonpreferred" vendor, (b) for a larger quantity of good or service than desired by the university, (c) for goods or services of a higher quality than desired, (d) made by an employee not authorized to use the p-card, or (e) not properly authorized by supervisory personnel (when required) prior to the purchase.

When university management lacks confidence in its p-card control structure, we find that the university is more likely to (a) lower the level of card distribution to employees, (b) lower monthly and pertransaction spending limits, and (c) operate with an administrative focus to limit p-card spending. Compared to their peers, universities with higher concern reported 35\% lower average monthly p-card spending and significantly lower past and expected future card spending growth. Thus, simply the fear of misuse not only makes the program weaker in the present but sets a path of weakness for the future.

In reality, loss from card misuse relative to card spending has consistently been shown to be materially insignificant (in financial terms) on a market-wide scale (The Nilson Report, 2017). In the survey, university respondents noted an average loss to the university as a percentage of $p$-card spending from fraud and misrepresentation of $0.008 \%$ (or $\$ 80$ out of every $\$ 1$ million of card spending) and an average loss from policy violations of $0.008 \%$ (or $\$ 80$ out of every $\$ 1$ million of card spending). Regardless of the limited impact, the simple fear of an incident can paralyze a card program, reduce administration confidence in and support of the program, or cause changes in the configuration of the program that undermine the potential value gained from card use. To allay those fears, a program that includes carefully constructed controls is paramount. For example, those controls should address

- the potential for unrestrained or unapproved spending (e.g., by careful assignment of monthly and per-transaction spending limits);

- the types of goods and services allowed to be purchased with the p-card (e.g., by restrictions of card use to specific card-accepting vendors classified under certain Merchant Category Codes);

- the qualifications of the employee or the type of position to hold a p-card;

- the need for a clear organizational policy statement regarding proper card use;

- other restrictions that may be applied to card spending (e.g. limits on the times, days, or geographic locations in which cards may be used, or automated denial of "back-to-back" purchases at the same vendor to circumvent capitalization policies);

- other activities to manage the card program, such as deactivating p-card accounts unused for an extended time, data-mining transactions for unusual patterns, and investing in issuerprovided insurance against fraudulent card use.

PALMER, GUPTA, \& BRANDT / DOI: 10.5929/2019.1.14.4 
Table 3 provides some benchmark norms for control activities, showing that large universities have average monthly and per-transaction spending limits that are larger than their smaller counterparts. By contrast, small universities are more likely to customize spending limits to individual cardholder spending needs. Another aspect of card program control that differs between the groups is the commitment to training, with smaller universities less likely to require initial $p$-card training for their cardholders, but more likely to require periodic refresher training.

Table 3

Select Management Statistics of P-Card Program Control by Size of University

\begin{tabular}{lrrr}
\hline Spending Limit Statistics & Small & Mid-Size & Large \\
\hline Average monthly card spending limit & $\$ 3,362$ & $\$ 6,828$ & $\$ 9,303$ \\
$\quad \begin{array}{l}\text { Average per-transaction limit } \\
\text { Percentage that customize spending limits to individual } \\
\text { cardholder spending needs }\end{array}$ & $\$ 1,334$ & $\$ 2,217$ & $\$ 2,858$ \\
\hline Required Cardholder Training & $71 \%$ & $66 \%$ & $64 \%$ \\
\hline Percentage that require initial training & & & \\
$\quad$ Percentage that require periodic refresher training & $75 \%$ & $92 \%$ & $96 \%$ \\
& $63 \%$ & $48 \%$ & $36 \%$ \\
\hline
\end{tabular}

\section{Technology}

Successful p-card implementation is associated with greater levels of activity to integrate the innovation with other technologies and organizational processes. In the case of p-cards, 2017 survey data shows that $72 \%$ of high-performing p-card programs (among all organization types) had fully integrated "data feeds" from card issuers into their accounting systems. These organizations made use of program-supportive technology (like data mining and expense management software) and adopted use of other card-based technologies like electronic accounts payable (also known as "EAP" or "virtual cards" which are non-plastic card accounts used to pay for goods and services after an invoice has been received for those goods or services).

P-card use may be elevated by complementary card and non-card technology. In Table 4 benchmark survey data indicates that larger universities are more likely to (a) use web-based applications for training and communicating with cardholders, (b) adopt and use other card platforms (EAP and ghost/cardless accounts) in addition to plastic cards to capture higher dollar transactions, (c) convert receipts and expense documentation into an electronic format, (d) have card data fully integrated with accounting systems, and (e) use card reporting technology to data mine transactions and notify managers of potential fraud.

As discussed, obstacles in program implementation arise when universities do not incorporate fundamental management steps to help shape the outcome of $p$-card implementation. Those obstacles are thematically associated with card acceptance, control, and technology. Consideration of challenges to these foundational components is important in successfully implementing a $p$-card program that retains and builds card value.

PALMER, GUPTA, \& BRANDT / DOI: 10.5929/2019.1.14.4 
Table 4

Select Management Statistics of P-Card Program Technology by Size of University

\begin{tabular}{lrrr}
\hline Use of Web-Based Applications & Small & Mid-Size & Large \\
\hline $\begin{array}{l}\text { Percentage that provide web-based p-card training } \\
\text { Percentage that have a website that answers common p-card }\end{array}$ & $13 \%$ & $42 \%$ & $82 \%$ \\
program questions & $38 \%$ & $63 \%$ & $91 \%$ \\
\hline P-Card Platforms & & & \\
\hline $\begin{array}{l}\text { Percentage that use EAP } \\
\text { Percentage that use Ghost or cardless accounts }\end{array}$ & $9 \%$ & $13 \%$ & $34 \%$ \\
\hline Receipt Retention Policy & & $12 \%$ & $35 \%$ \\
\hline $\begin{array}{l}\text { Percentage that scan/photograph receipts into an electronic } \\
\text { format }\end{array}$ & $20 \%$ & $43 \%$ & $46 \%$ \\
\hline Card Data Integration & & & \\
\hline $\begin{array}{l}\text { Percentage that have fully integrated p-card data with } \\
\text { accounting systems }\end{array}$ & $20 \%$ & $69 \%$ & $91 \%$ \\
\hline $\begin{array}{l}\text { Card Reporting Tools } \\
\text { Percentage that use card reporting technology to... }\end{array}$ & $25 \%$ & $48 \%$ & $82 \%$ \\
\hline $\begin{array}{l}\text { Conduct data mining of p-card transactions } \\
\text { Immediately notify managers of a potentially fraudulent or } \\
\text { policy-violating transaction after it occurs }\end{array}$ & $63 \%$ & $67 \%$ & $73 \%$ \\
\hline
\end{tabular}

\section{A Roadmap for Program Rehabilitation}

As noted earlier, most technology implementations fail, and p-card programs are no exception. P-card implementation is a type of Gordian knot. Specifically, most of the value derived from p-card implementation is positively correlated with the amount of spending driven to the card; but poorly implemented p-card programs yield low spending on cards (and less value). Consequently, the organization adopting $\mathrm{p}$-cards but ineffectually implementing their use may see little value from the program and are less likely to invest their time and resources to make course corrections to alter the trajectory of the implementation.

The solution lies with information and education. Figure 2 presents a framework of nine steps to help a university transform a lethargic underperforming program into one that rises to a virtuous cycle. The framework is rooted in the three pillars for p-card program success (acceptance, control, and technology), the common obstacles to successful implementations, and over twenty years of our research and discussions with high-performing p-card program administrators. The key steps are as follows:

- Assess the current state and review choices that led there. Understand and objectively assess the current state of the p-card program. Specifically, obtain access to university-specific benchmark norms and "best practice" configurations for comparison and critical analysis.

- Find a community. No need to "reinvent the wheel." Insight can be obtained from other universities that have overcome barriers to achieve significant and enduring value from $p$ card use. This information can be gained through expanding the university's professional network and interactions at relevant card user conferences.

PALMER, GUPTA, \& BRANDT / DOI: 10.5929/2019.1.14.4 
- Address the fear. Educate university leadership to overcome the fear factor. Many administrators operate in a preternaturally defensive mode, focusing on "what can go wrong," and not on "how can we get it right." Clearly and regularly communicate each aspect of the p-card value proposition and every lever of control over cardholder activity. Put potential misuse in the context of benefits to the university from card use. Few administrators will support losing the proverbial dollar to control a dime when data is brought to light. Demonstrate an action plan and ready set of process steps to respond to any potential occurrence of misuse.

- Create a "safe space" for p-card use and experimentation. No one will support a program that lacks proper control or does not appear to comply with university policy. The most effective route for change is to bring known and well-established p-card control configurations from peers to the attention of compliance and control advocates in the organization (e.g., Internal Audit) for review and critique.

- On-board employees. Employees can be hesitant to jump on the p-card "train" if they do not see the organizational interest and card-supportive policies. Consider a card distribution policy that focuses on individuals who would benefit the most from a card, thus creating card "evangelists" within the organization. Others will want in upon hearing of the simplicity and benefits of card-enabled purchases. Develop policies that encourage card use as the preferred payment option.

- Exploit technology. Card data should be seamlessly integrated with university systems (work with the issuer to make that happen). Data analytic technologies not only highlight growth opportunities but also strengthen control over card use, providing greater comfort to management and users. EAP and mobile applications open a whole new terrain for cardsupported spending.

- Set targets. Define the goals for the p-card program (e.g., cycle time, working capital float, savings achieved, discounts captured). Measure performance tied to those goals on a regular basis.

- On-board suppliers. Card users report being limited by suppliers reticent to accept card payment. Work with the card issuer to identify vendors that accept card payment (that the university is currently paying by check). Identify suppliers to whom many small checks are written and begin a dialogue that informs them of the benefits they receive by accepting card payment. When feasible, switch vendors based on card acceptance.

- Report progress; celebrate successes. Communicate progress of the card program toward the goals set forth. Share the story both internally and externally and take pride in the program successes. 


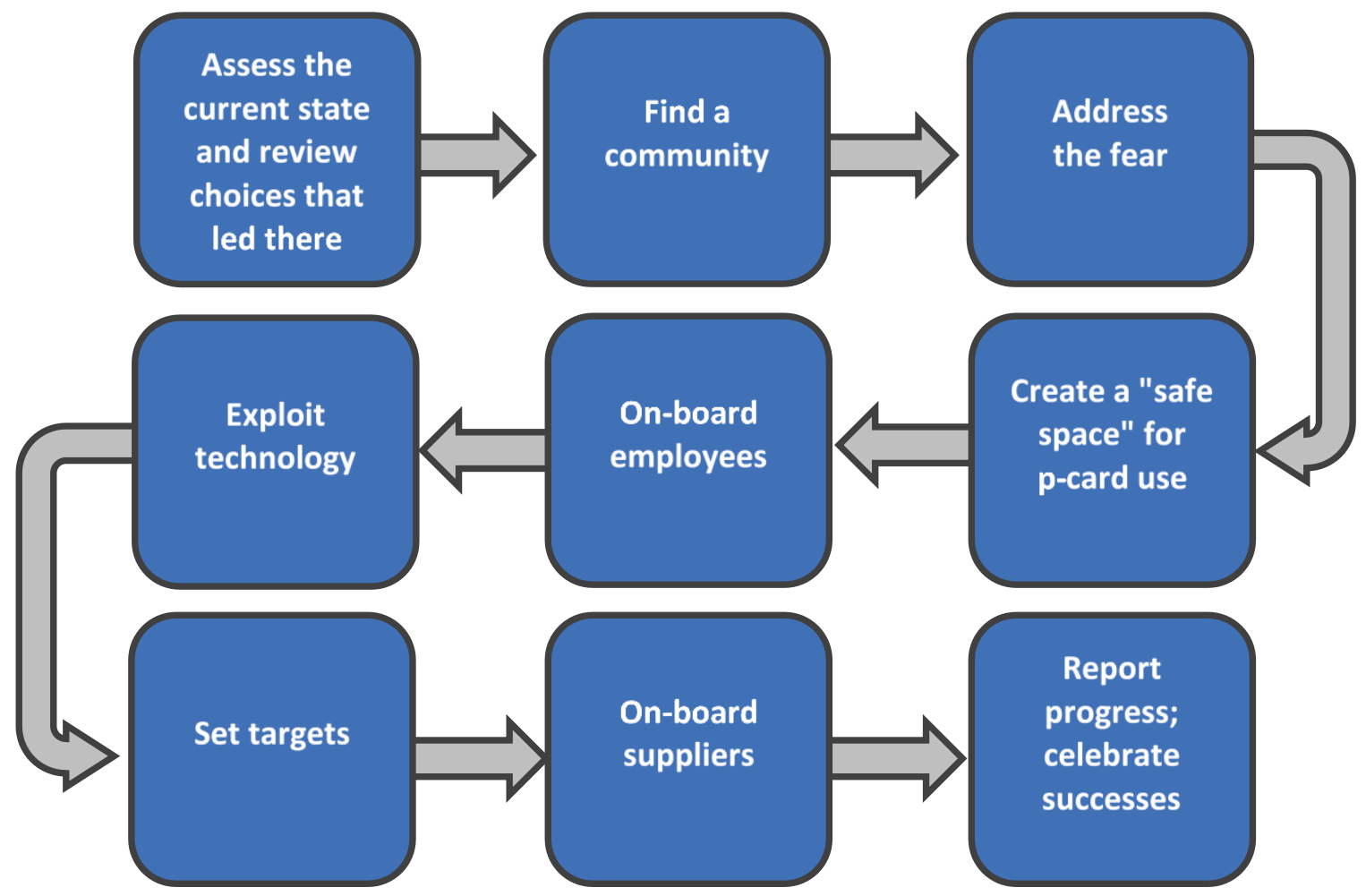

Figure 2. A Framework to Promote and Sustain P-Card Program Value

\section{Conclusion}

The purpose of this paper was to provide evidence-based insight to (a) highlight the problem of p-card program implementation failure among universities, (b) present a $p$-card program self-assessment methodology, (c) identify obstacles that universities faced in implementing a successful p-card program, and (d) provide a framework to rehabilitate underperforming p-card programs. Through the employment of peer-tested countermeasures, many of the obstacles to program success can be overcome-promoting continued robust growth that protects the university's resources while maximizing the value delivered by $p$-cards.

\section{References}

Aiman-Smith, L., \& Green, S. G. (2002). Implementing new manufacturing technology: The related effects of technology characteristics and user learning activities. Academy of Management Journal, 45, 421-430.

Baer, M., \& Frese, M. (2003). Innovation is not enough: Climates for initiative and psychological safety, process innovations, and firm performance. Journal of Organizational Behavior, 24, 45-68.

Bottomline Technologies \& BNY Mellon. (2017). Treasury's role in transforming accounts payable into a profit center. Retrieved from https://www.bnymellon.com/ global-assets/pdf/solutionsindex/treasury-role-in-transforming-accounts-payable-into-profit-center.pdf

Herbst-Murphy, S. (2011). Getting down to business: Commercial cards in business-to-business payments. Discussion paper, Payment Cards Center, Federal Reserve Bank of Philadelphia. 
Klein, K. J., \& Knight, A. P. (2005). Innovation implementation. Current Directions in Psychological Science, 14(5), 243-246.

Paystream Advisors (2012). The value of purchasing cards. Retrieved from http://docs.usbpayment.com/Value\%20of\%20Purchasing\%20Cards\%20Report\%20-\%20U.S.\%20 Bank\%20and\%20PayStream.pdf

Repenning, N. P., \& Sterman, J. D. (2002). Capability traps and self-confirming attribution errors in the dynamics of process improvement. Administrative Science Quarterly, 47, 265-295.

The Nilson Report. (2017, October). Card Fraud Losses Reach $\$ 22.80$ Billion. The Nilson Report, 47 (1118). Retrieved from https://nilsonreport.com/upload/content promo/The Nilson Report Issue 1118.pdf

Thorpe, W. K. (2016). The benefits of using purchasing cards. CFO Edge (May 18). Retrieved from https://www.cfoedge.com/blog/cash-advisory/ar-ap-management/the-benefits-of-usingpurchasing-cards/

About the Authors

Richard J. Palmer (rpalmer@semo.edu) is a Professor of Accounting and Copper Dome Faculty Fellow in the Harrison College of Business at Southeast Missouri State University. Previously, he held teaching positions at Washington University in St. Louis, Eastern Illinois University, and the University of Tennessee, as well as management positions in both public accounting and the banking industry. He is a frequent speaker at commercial card conferences and is the author of over 60 professional and academic publications, including award-winning articles about industry use of e-procurement tools and bank commercial cards. His insights on card use have been quoted in national news outlets such as the Wall Street Journal, Good Morning America, CNN Money, and Market Watch.

Mahendra Gupta (m.gupta@wustl.edu) is a Virgil Professor of Accounting and Management at the Olin School of Business at Washington University in St. Louis. He received his Ph.D. from Stanford University and M.S. from Carnegie Mellon University. He has been a consultant to various financial service and manufacturing firms, as well as government agencies. His writings have appeared in top accounting and management journals. Professor Gupta also served on the editorial board of several top journals in the accounting profession and currently serves on the board of several organizations. He has written extensively and speaks frequently on e-commerce, performance measurement, and commercial card products.

James Brandt (jbrandt@RPMGresearch.net) is the Senior Research Analyst at RPMG. He received his B.S.B.A. in Accountancy and M.B.A. with honors from Southeast Missouri State University. James has conducted commercial card and e-commerce research with RPMG since 2011. He has co-authored articles featured in Cost Management, the Journal of Payments Strategy \& Systems, and NIGP. In addition, he has spoken at commercial card conferences and previously spent three years in public accounting and one year teaching in higher education.

PALMER, GUPTA, \& BRANDT / DOI: 10.5929/2019.1.14.4 